Original Article

\title{
Intra-rater reliability when using a tympanic thermometer under different self-measurement conditions
}

\author{
WON-GYU YOO ${ }^{1)}$ \\ 1) Department of Physical Therapy, College of Biomedical Science and Engineering, Inje University: \\ 607 Obangdong, Gimhae, Gyeongsangnam-do 621-749, Republic of Korea
}

\begin{abstract}
Purpose] This study investigated intra-rater reliability when using a tympanic thermometer under different self-measurement conditions. [Subjects and Methods] Ten males participated. Intra-rater reliability was assessed by comparing the values under three conditions of measurement using a tympanic thermometer. Intraclass correlation coefficients were used to assess intra-rater reliability. [Results] According to the intraclass correlation coefficient analysis, reliability could be ranked according to the conditions of measurement. [Conclusion] The results showed that self-measurement of body temperature is more precise when combined with common sense and basic education about the anatomy of the eardrum.

Key words: Intra-rater reliability, Self-measurement, Tympanic thermometer
\end{abstract}

(This article was submitted Feb. 14, 2016, and was accepted Apr. 7, 2016)

\section{INTRODUCTION}

Smitz et al. reported that predictive accuracy depends on both operator technique and quality of instrumentation ${ }^{1)}$. Thus, expensive equipment for precise measurement of temperature, such as digital infrared thermographic imaging devices, was necessary for use in research ${ }^{2}$. However, in clinical use, the need for expensive equipment to measure temperature is limited, and therefore tympanic thermometers are popular and commonly used. The tympanic thermometer measures body temperature using infrared rays ${ }^{3}$. The eardrum is a readily accessible hypothalamic thermostat, and therefore measuring the temperature of the eardrum is theoretically very precise ${ }^{4}$. Zhen et al. reported that the accuracy of infrared ear thermometry in children is poor, and cannot replace rectal thermometry in clinical pediatric practice ${ }^{3)}$. Many authors still recommend measuring rectal or oral temperature when precise body temperature is required ${ }^{1,3,5)}$. However, in measuring rectal and oral temperatures, hygienic management of the thermometer is difficult, and more time is needed to measure temperature. Thus, this study investigated intra-rater reliability when using a tympanic thermometer under different self-measurement conditions.

\section{SUBJECTS AND METHODS}

The study subjects included 10 males aged $25.0 \pm 2.1$ years (mean $\pm \mathrm{SD}$ ), with a mean height and weight of $174.2 \pm 2.5 \mathrm{~cm}$ and $65.5 \pm 5.3 \mathrm{~kg}$, respectively. The subjects received an explanation about the purpose and methods of the study prior to participation and provided informed consent according to the principles of the Declaration of Helsinki. In this study, body temperature was measured with a tympanic thermometer in current use by hospitals and produced by B company. Body temperature was measured under the following three conditions. Condition 1: passive measurement by professional medical staff; condition 2: self-measurement before learning measurement technique using a tympanic thermometer; condition 3: self- 
measurement after learning measurement technique using a tympanic thermometer. A professional nurse with more than three years of experience measured the temperature under condition 1. Body temperature of the ten subjects was then measured under condition 2. After watching a 5-minute video describing measurement technique using a tympanic thermometer and eardrum anatomy, body temperature was measured under condition 3. Intra-rater reliability using a tympanic thermometer was assessed by comparing the measured values under these three conditions of measurement. Intraclass correlation coefficients (ICCs) were used to assess intra-rater reliability under the three conditions.

\section{RESULTS}

According to the ICC analysis, reliability was high in the order of condition $3(0.97)$, condition $1(0.92)$, and condition 2 (0.90).

\section{DISCUSSION}

The shape of the eardrum differs among individuals, and a tympanic thermometer is designed for non-experts to use to measure temperature ${ }^{3,4)}$. Self-measurement of body temperature is more precise when combined with common sense and basic education about the anatomy of the eardrum. Use of a tympanic thermometer in children or patients with a mental disorder is difficult; however, in the case of adult patients hospitalized for a prolonged period because of a febrile illness, self-measurement data should be taken into account along with measurement by a professional. In addition, a tympanic thermometer is designed to present the highest of multiple readings as the measured value ${ }^{4}$. Statistical analysis was not performed, but the average of the measured values under condition 3 was highest. If simple common sense combined with knowledge of the anatomy of the eardrum is applied to the technique of temperature measurement using a tympanic thermometer distributed to caregivers, precision of use will be enhanced for both adults and children.

\section{REFERENCES}

1) Smitz S, Van de Winckel A, Smitz MF: Reliability of infrared ear thermometry in the prediction of rectal temperature in older inpatients. J Clin Nurs, 2009, 18: 451-456. [Medline] [CrossRef]

2) Namkoong S, Shim J, Kim S, et al.: Effects of different sitting positions on skin temperature of the lower extremity. J Phys Ther Sci, 2015, 27: 2637-2640. [Medline] [CrossRef]

3) Zhen C, Xia Z, Long L, et al.: Accuracy of infrared ear thermometry in children: a meta-analysis and systematic review. Clin Pediatr (Phila), 2014, 53: 1158-1165. [Medline] [CrossRef]

4) Stavem K, Saxholm H, Smith-Erichsen N: Accuracy of infrared ear thermometry in adult patients. Intensive Care Med, 1997, 23: 100-105. [Medline] [CrossRef]

5) Dodd SR, Lancaster GA, Craig JV, et al.: In a systematic review, infrared ear thermometry for fever diagnosis in children finds poor sensitivity. J Clin Epidemiol, 2006, 59: 354-357. [Medline] [CrossRef] 